\title{
Pharmacotherapy of Panic Disorder: Proposed Guidelines for the Family Physician
}

\author{
Peter Roy-Byrne, MD, Murray Stein, MD, Alexander Bystrisky, MD, and Wayne Katon, $M D$
}

Background: Efforts to improve the recognition and treatment of panic disorder in the primary care setting have not resulted in better outcomes. Studies show that even when physicians recognize panic disorder, they do not treat it adequately. Family physicians need specific diagnostic and treatment guidelines when they encounter a patient who has possible panic disorder.

Methods: Four psychiatrists with expertise in the pharmacotherapy of panic disorder and experience working in the primary care setting reviewed the available treatment literature and developed a consensus treatment algorithm for panic pharmacotherapy in the primary care setting. These proposed guidelines were reviewed for accuracy by 3 additional psychiatric experts and for their applicability to the primary care setting by 2 leading experts on the treatment of mental disorders in primary care.

Results: Guidelines for medication selection, dosing, titration, side-effect management, and maintenance treatment are proposed. Modifications for patients already on psychotropic medication are provided, and indications for psychiatric consultation are specified.

Conclusions: Panic disorder is a highly treatable condition, and primary care physicians can deliver effective pharmacotherapy if specific guidelines are carefully followed. (J Am Board Fam Pract 1998;11:282-90.)

With a prevalence of approximately 6 to 8 percent according to the most well-designed studies, ${ }^{1-4}$ panic disorder is the most commonly encountered anxiety disorder in the primary care setting. Eighty-five percent of patients with panic disorder initially seek care in the general medical setting. ${ }^{5}$ Panic disorder occurs less often than depression in primary care, and primary care physicians are less effective at recognizing anxiety compared with depression. ${ }^{6}$ In one study 70 percent of 57 patients with panic disorder saw an average of 10 physicians before finally having their condition diagnosed. ${ }^{7}$

Because panic disorder so closely mimics medical disorders requiring acute treatment, primary care physicians are often distracted by concerns they will fail to recognize emergent medical conditions such as cardiac ischemia. High utilization

Submitted, revised, 22 October 1997.

From the Department of Psychiatry and Behavioral Sciences (PRB, WK), University of Washington School of Medicine, Seattle, the Department of Psychiatry (MS), University of California at San Diego, and the Department of Psychiatry (AB), University of California at Los Angeles. Address reprint requests to Peter Roy-Byrne, MD, Department of Psychiatry and Behavioral Sciences, Harborview Medical Center, 325 Ninth Ave, Box 359911, Seattle, WA 98104. of health care services and costly medical procedures $^{8}$ ensue as physicians seek to account for unexplained symptoms of chest pain, palpitations, shortness of breath, nausea, diarrhea, headache, and dizziness. Physical examination can also reveal worrisome signs, such as labile hypertension or tachycardia, which can lead to extensive medical testing. Untreated panic disorder is equally or more disabling than depressive disorder ${ }^{9}$ and causes substantial impairment in quality of life. ${ }^{10}$

Unfortunately efforts to increase recognition of panic and other anxiety disorders have not resulted in better outcomes, and recent studies show that even when panic disorder and other anxiety disorders are diagnosed, they are still inadequately treated. ${ }^{11}$ Only one study provides suggestive data on antipanic treatment in primary care, showing that minor tranquilizers were used more often (10 to 30 percent) than antidepressants ( 5 to 24 percent) for patients with either panic, generalized anxiety disorder (ie, free-floating anxiety without panic or phobia), or phobia. ${ }^{12}$ Furthermore, appropriate concern about the addictive potential of benzodiazepines ${ }^{13}$ often leads physicians to prescribe them on an as-needed rather than a regularly scheduled basis and at doses too low for ade- 
quate efficacy. Ironically, as-needed use of short half-life benzodiazepines can actually worsen the course of panic disorder. ${ }^{14}$

\section{Methods}

We provide a brief overview of methods to diagnose panic disorder and follow with specific guidelines for the primary care physician seeking to care for patients with panic disorder in the primary care setting. After reviewing the importance of and strategies for explaining the diagnosis and rationale for treatment to the patient and providing a system for monitoring the effects of treatment, we describe specific pharmacotherapeutic guidelines for titration, side-effect management, maintenance treatment, taper and discontinuation, adjustments in approach for patients needing treatment who are already on psychotropic medication, and when to refer to a psychiatrist.

These guidelines are based on an extensive review of the literature, using the key words "panic disorder," "treatment," "pharmacotherapy," and "medication." The guidelines were then reviewed for accuracy by 3 leading psychiatric experts in the pharmacotherapy of panic and for their applicability to the primary care setting by 2 leading experts on the treatment of mental disorders in primary care.

\section{Making the Diagnosis}

The diagnosis of panic disorder requires that the patient experience at least two panic attacks and either persistent worry about having attacks or a change in behavior or attitude because of attacks (eg, avoiding certain situations for fear of having an attack [agoraphobia] or being preoccupied with other imagined consequences of attacks, such as ill health or fears of undiscovered medical illness [hypochondriasis]).

Our group has found that the following two screening questions, adapted from the Composite International Diagnostic Interview ${ }^{15}$ with modifications by one of the authors (WK), are highly sensitive but not specific: (1) Did you ever have a spell or attack when all of a sudden you felt frightened, anxious, or very uneasy? (2) Did you ever have a spell or attack when for no reason your heart began to race, you felt faint or nauseous, or you could not catch your breath? If the answer is no, the patient almost certainly does not have panic disorder. If the answer is yes, there is a 25

\section{Table 1. Criteria for Panic Attack.*}

Chest pain or discomfort

Chills or hot flashes

Derealization (feclings of unreality) or depersonalization (being detached from oneself)

Fear of dying

Fear of losing control or going crazy

Feeling dizzy, unsteady, lightheaded, or faint

Feeling of choking

Nausea or abdominal distress

Palpitations, pounding heart, or accelerated heart rate

Paraesthesias (numbness or tingling sensations)

Sensations of shortness of breath or smothering

Sweating

Trembling or shaking

"A discrete period of intense fear or discomfort during which four (or more) of the following symptoms developed abruptly and reached a peak within 10 minutes.

Adapted from The Diagnostic and Statistical Manual of Mental Disoralers (DSM-IV). ${ }^{16}$

percent likelihood of having panic. Based on unpublished data collected at three separate primary care clinic sites, another third probably have depression or anxiety or substance use disorder, and one third probably have no disorder.

To make the diagnosis of panic disorder, it is important to find out whether the patient has at least 4 of 13 panic symptoms (Table 1), whether at least some attacks occur unpredictably (without a fear-inducing stimulus), whether attacks are confined to social situations (the diagnosis would be social phobia, not panic, if the attacks occurred only in social situations), and whether attacks build to a peak in 5 to 10 minutes and wear off (at least somewhat) within the hour. The Diagnostic and Statistical Manual of Mental Disorders (DSMIV) ${ }^{16}$ criteria for a panic attack are listed in Table 1. More structured interviews are available but are too cumbersome for routine use. The PRIME$M^{17}$ contains a screening item for panic disorder that is quite similar to our first screening item and a diagnostic module for panic disorder that is more simple than standard psychiatric diagnostic interviews, such as the Structure Clinical Interview for DSM-IV (SCID), but it still requires some time (10 to 15 minutes).

\section{The Initial Step: Careful Explanation of Diagnosis}

Adequate explanation of the medical nature of panic disorder is the major and central determi- 
nant of subsequent treatment success or failure. Often patients have had multiple medical evaluations for their symptoms and have repeatedly been told that "it's all in your head." An explanation that panic disorder is indeed a medical disorder, not in the patient's head and is not the patient's fault, is crucial. A medicophysiologic model can sometimes be helpful. We often tell patients that there is a stress thermostat in the brain, that the set point has been elevated by accumulating life stresses, and that the thermostat function is now maintaining the patient at a stress level which is too high. This explanation emphasizes the problem as one of brain regulation, not damage or deficiency, and helps account for the slower action of medications or other therapies; that is, they are working to reset the stress thermostat by reinitiating a normal balancing mechanism. A more simple explanation is that the condition is caused by an instability of the autonomic nervous system in which a flight or fight alarm goes off too easily with inadequate reason.

Whatever explanation is chosen, care must be taken not to convey to patients that they have no control over their condition and that psychotherapy or other measures designed to increase their coping skills are unimportant. Stress and environmental factors can trigger ${ }^{18}$ and keep active ${ }^{19}$ the expression of an underlying biogenetic vulnerability. The importance of nonmedical interventions can be emphasized by analogy to rehabilitation after medical or surgical procedures for managing orthopedic injuries or to diet and lifestyle change after medication interventions for managing diabetes, hypertension, and other cardiac problems. The patient can be told that medical treatment can begin and the need for formal psychologic intervention can be evaluated several weeks to months later to determine whether psychotherapy is required.

These simple introductory strategies provide an explanatory model that will help the patient gain some control over their condition. It is also important to counter the demoralization resulting from past experiences with unproductive medical evaluations during which patients were told nothing's wrong or "its all in your head." Negative thinking and an apprehensive attitude could lie behind the greater tendency of panic disorder patients to experience adverse side effects when given placebos (up to four times greater than de- pressed patients ${ }^{20}$ ), suggesting that perhaps some component of medication intolerance is not pharmacologically based. For this reason, the physician must be careful not to give too detailed an explanation of medication side effects. The most common side effects should be mentioned to patients with instructions to telephone immediately if any other symptom arises of concern to the patient.

Providing patients with reading materials about panic disorder also enhances their sense of selfcontrol. Pamphlets are available from the National Institute of Mental Health by writing to: National Institute of Mental Health, Panic Disorders Education Program, 5600 Fischers Lane, Room 7C02, Rockville, MD 20857, or calling toll free 1800-64 PANIC. Numerous books written for patients and their families can be found in the psychology or self-help sections of major book stores.

\section{The Next Step: A Monitoring System}

Before starting treatment, a baseline record of the most salient symptoms and the degree to which they occur must be established so that treatment can be monitored accurately. Panic disorder is a multifaceted syndrome that consists of varying combinations of panic attacks, anticipatory anxiety (fear of future panic attacks), phobic avoidance, preoccupation with and anxiety about health, depression, and certain degrees of both social and occupational disabilities. Because initially a partial response to treatment can be more the rule than the exception, it is essential to quantify symptoms during treatment to allow both physician and patient to know that they are on the right track, to determine the symptom areas that are most responsive, and to recognize refractory areas that might require additional pharmacotherapy or psychotherapeutic intervention.

Most available rating scales are cumbersome and address only individual components of the panic syndrome (eg, general anxiety, phobic avoidance, panic frequency). A good compromise is to have the patient use a customized diary to record daily the number, duration, and intensity of episodic panic attacks, along with the intensity of other more consistently present symptoms. Figure 1 is an example of such a diary. Patients who have chronic symptoms that are prominently somatic, such as chest pain or palpitation, should also record these symptoms on the daily rating scale. 


\section{PANIC DISORDER RATING SCALE}

Name

Start Date

Write in number using scale below as guideline (except for number of panic attacks)

\begin{tabular}{|c|c|c|c|c|c|c|c|c|c|c|c|c|c|c|c|c|c|c|c|c|c|}
\hline & Mon 1 & Tue $\mid$ W & Ned Thu & \begin{tabular}{l|l} 
u Fri
\end{tabular} & Sat & it Sun & Mon & Tue We & Ved Thu & a Fri & Sat & $\operatorname{sun} 1$ & \begin{tabular}{|l|l|l} 
Mon Tue \\
\end{tabular} & ue Wed Thu & iu Fri & Sat s & $\operatorname{Sun} M$ & Mon Tue & Wed Thu & Fri $S$ & Sat Sun \\
\hline Panic attacks (number) & & & & & & & & & & & & & & & & & & & & & \\
\hline Panic attack intensity & & & & & & & & & & & & & & & & & & & & & \\
\hline Anxiety about attacks & & & & & & & & & & & & & & & & & & & & & \\
\hline Anxiety about health & & & & & & & & & & & & & & & & & & & & & \\
\hline General anxiety & & & & & & & & & & & & & & & & & & & & & \\
\hline Fear of & & & & & & & & & & & & & & & & & & & & & \\
\hline Avoidance of & & & & & & & & & & & & & & & & & & & & & \\
\hline Depression & & & & & & & & & & & & & & & & & & & & & \\
\hline Role impairment & & & & & & & & & & & & & & & & & & & & & \\
\hline Relationship impairment & & & & & & & & & & & & & & & & & & & & & \\
\hline Dissatisfaction with life & & & & & & & & & & & & & & & & & & & & & \\
\hline & & & & & & & & & & & & & & & & & & & & & \\
\hline
\end{tabular}

SCALE FOR RATING SEVERITY

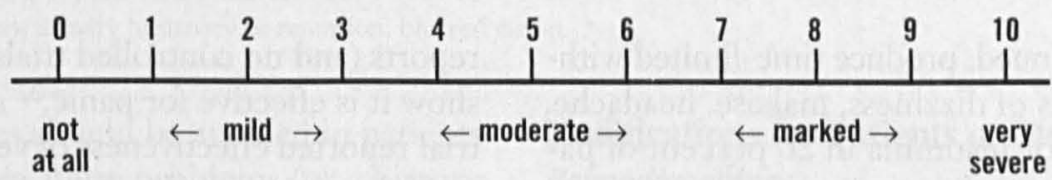

Figure 1. Panic disorder rating scale.

Patients must be encouraged to understand the importance of keeping a daily diary, which takes only a few minutes each evening. By having the patient begin the diary several days before starting treatment, any fluctuating pattern to panic attacks or other somatic symptoms will not immediately be attributed to newly prescribed medication. Recently a more standardized 7-item scale, the Panic Disorder Severity Scale (PDSS), ${ }^{21}$ which uses single items to measure the multiple components of the panic syndrome, has proved valid and highly reliable. Items are rated from 0 (none) to 4 (most severe) with a descriptor provided for each, and preliminary studies show these items decrease with treatment.

A final strategy to facilitate accurate monitoring is to encourage patients to report briefly on their progress by telephone once or twice during the first week. We ask particularly apprehensive patients to telephone at a specific time the day after starting medication, even if there are no problems. This strategy desensitizes patients to any mild side effects, allows a scheduled time for them to ask questions they might otherwise feel too foolish to telephone about spontaneously, and cements a sense of active collaboration with the physician in treating the disorder. Such telephone calls take only a few minutes and do much to obviate premature discontinuation of medication or emergency visits later during the course of treatment.

The proposed treatment algorithm assumes an 8-week period for initial treatment with follow-up visits planned 2, 4, and 8 weeks after the initial baseline visit.

\section{Selection of Medication}

Selection of medication depends on whether patients have ever received pharmacotherapy for the treatment of a mood or anxiety disorder.

\section{No Treatment History}

A selective serotonin reuptake inhibitor (SSRI) is the treatment of choice for patients who have never had pharmacotherapy. All four SSRIs are thought to be effective for panic disorder; they differ only in subtle side-effect profiles, how they influence the cytochrome P-450 liver enzyme systems (which can alter blood levels of medications prescribed for other medical conditions), and the duration of half-life (short half-life SSRIs, when 
Table 2. Efficacy, Advantages, and Disadvantages of Available Selective Serotonin Reuptake Inhibitors (SSRIs).

\begin{tabular}{llll}
\hline Drug & Antipanic Efficacy & Advantages & Disadvantages \\
\hline $\begin{array}{l}\text { Fluoxetine } \\
\text { (Prozac) }\end{array}$ & First US efficacy reports & $\begin{array}{l}\text { Elixir for slow titration } \\
\text { Long half-life (no } \\
\text { withdrawal) } \\
\text { No P-450 2D6 effects }\end{array}$ & $\begin{array}{l}\text { More stimulating } \\
\text { Longer half-life (hard to wash out } \\
\text { drug) }\end{array}$ \\
$\begin{array}{l}\text { Fluvoxamine } \\
\text { (Luvox) }\end{array}$ & $\begin{array}{l}\text { Most double-blind } \\
\text { treatment data }\end{array}$ & $\begin{array}{l}\text { Twice daily dosing required } \\
\text { Effects on P-450 1A2, 2C9, and 3A4 } \\
\text { Short half-life }\end{array}$ \\
$\begin{array}{l}\text { Paroxetine } \\
\text { (Paxil) }\end{array}$ & FDA approved & $\begin{array}{l}\text { Least stimulating } \\
\text { Minimal P-450 3A4 effects }\end{array}$ & $\begin{array}{l}\text { More anticholinergic } \\
\text { More sedating } \\
\text { Short half-life }\end{array}$ \\
$\begin{array}{l}\text { Sertraline } \\
\text { (Zoloft) }\end{array}$ & FDA approved & $\begin{array}{l}\text { Fewest P-450 2D6 effects } \\
\text { Minimal P-450 3A4 effects } \\
\text { Intermediate half-life } \\
\text { (less withdrawal) }\end{array}$ & $\begin{array}{l}\text { More diarrhea and } \\
\text { gastrointestinal upset }\end{array}$ \\
& & &
\end{tabular}

FDA - Food and Drug Administration.

Medications affected by SSRI inhibitions of different cytochrome P-450 enzyme systems:

$1 \mathrm{~A} 2$ - Increases levels of theophylline, clozapine, haloperidol, amitriptyline, clomipramine, imipramine, caffeine, warfarin, propranolol.

2C9 - Increases levels of diazepam, tolbutamide, phenytoin.

2D6 - Increases levels of tricyclic antidepressants, type C antiarrhythmics, haloperidol, trazodone.

3A4 - Increases levels of carbamazepine, alprazolam, terfenadine, astemizole, midazolam, triazolam.

abruptly discontinued, produce time-limited withdrawal symptoms of dizziness, malaise, headache, nausea, fatigue, or insomnia in 20 percent of patients). Table 2 summarizes salient data on the four currently available SSRIs. A safe rule for prescribing SSRIs with other medications is to check serum levels of medications that require serum level monitoring (such as phenytoin, theophylline, digoxin) within 1 to 2 weeks after starting an SSRI.

\section{Previous Medication Treatment}

If the patient had a positive response to an antidepressant prescribed in the past and prefers it, this antidepressant should be used regardless of whether it is an SSRI or a tricyclic antidepressant. If the previous medication is a tricyclic antidepressant, nortriptyline is preferred because of its lower anticholinergic and orthostatic hypotensive effects compared with imipramine, doxepin, and amitriptyline, its greater sleep-promoting effects compared with desipramine, and its more easily interpretable blood levels. If the patient had a positive response to a benzodiazepine, choose an SSRI.

If the patient has a history of no response to a tricyclic antidepressant or benzodiazepine, choose an SSRI. If a patient had no response or was intolerant to one SSRI, choose a different SSRI. If a patient had either no response or side effects to two SSRIs, choose a tricyclic antidepressant (nortriptyline is preferred). Nefazodone or venlafaxine are also possible choices, although only anecdotal reports (and no controlled trials) with nefazodone show it is effective for panic, ${ }^{22}$ and one controlled trial reported effectiveness of venlafaxine. ${ }^{23}$

If the patient suffers from bipolar mood disorder and is taking thymoleptic medication, see Thymoleptics, discussed in Modifications for $\mathrm{Pa}$ tients on Medication.

\section{Antidepressants}

Selection among antidepressants should be based on the patient's panic symptom profile (avoid medications with similar side effects) and history of medication side effects (avoid reproducing previously problematic side effects). Table 3 displays adverse effects of recommended medications, and Table 4 lists management options for common side effects.

\section{Benzodiazepines}

Benzodiazepines are indicated if the patient has a history of nonresponse to most other antidepressants. Failure with two distinct classes of antidepressants is probably a minimum requirement. Benzodiazepines are also indicated if a medical illness contraindicates using other antidepressants (which would apply less to SSRIs than to other classes of antidepressants). If a patient's symptoms are disabling and require immediate attention (ie, when waiting 3 to 4 weeks for response will be too long for the patient), then a benzodiazepine would be appropriate. 
Table 3. Adverse Effects of Medications Used to Treat Panic Disorder.

\begin{tabular}{lccccccc}
\hline Adverse Effect & Fluoxetine & Sertraline & Paroxetine & Fluvoxamine & Nortriptyline & Nefizodone & Venlafaxinc* \\
\hline Headache & $\uparrow$ & - & - & - & $\downarrow$ & $\uparrow$ & - \\
Agitation and anxiety & $\uparrow \uparrow$ & $\uparrow$ & - & - & - & $\downarrow$ & $\uparrow \uparrow$ \\
Tremor & $\uparrow$ & $\uparrow$ & $\uparrow$ & - & $\uparrow \uparrow$ & $\downarrow$ & $\uparrow \uparrow$ \\
Insomnia & $\uparrow \uparrow$ & $\uparrow \uparrow$ & - & - & $\downarrow$ & $\downarrow$ & $\uparrow \uparrow$ \\
Drowsiness & $\uparrow$ & $\uparrow$ & $\uparrow \uparrow$ & $\uparrow \uparrow$ & $\uparrow \uparrow$ & $\uparrow \uparrow$ & $\uparrow \uparrow$ \\
Fatigue & $\uparrow$ & - & $\uparrow \uparrow$ & - & $\uparrow \uparrow$ & $\uparrow$ & $\uparrow$ \\
Confusion & - & - & - & - & - & $\uparrow \uparrow$ & - \\
Dizziness & - & - & $\uparrow$ & - & $\uparrow$ & $\uparrow \uparrow \uparrow$ & $\uparrow$ \\
Anticholinergic & - & - & $\uparrow$ & - & $\uparrow \uparrow \uparrow$ & - & - \\
Sweating & - & - & - & - & $\uparrow \uparrow$ & - & - \\
Weight gain & - & - & - & $\uparrow$ & $\uparrow$ & - & - \\
Nausea, gastrointestinal & $\uparrow$ & $\uparrow \uparrow$ & - & $\uparrow \uparrow$ & - & $\uparrow$ & $\uparrow \uparrow$ \\
Sexual & $\uparrow \uparrow$ & $\uparrow \uparrow$ & $\uparrow \uparrow$ & $\uparrow$ & $\uparrow$ & - & $\uparrow$ \\
\hline
\end{tabular}

Adapted from Preskorn. ${ }^{31}$

$\uparrow$ Increases occurrence.

$\downarrow$ Decreases occurrence.

${ }^{*}$ Can increase blood pressure; must be monitored.

tDry mouth, constipation, urinary hesitancy or retention, blurred vision.

Benzodiazepines should be avoided in patients who have substance abuse problems (or a history of substance abuse) or major concomitant depression. A psychiatrist should be consulted before prescribing benzodiazepines for these patients if other pharmacologic options do not work or cannot be tolerated.

Benzodiazepines might be preferred for some bipolar disorder patients with panic since antidepressants can precipitate mania or increase cyclicity of mood. ${ }^{24}$ Benzodiazepines may be added to antidepressant therapy for patients who are only partially responsive to therapy. Although cognitive behavioral therapy is likely to work equally well, the structured, multicomponent, cognitive behavioral therapy found to be effective in studies ${ }^{25}$ might be less available in primary care settings.

Preferred medications are alprazolam 2 to 6 $\mathrm{mg}$ (in divided doses three to four times daily) or clonazepam 1.5 to $4 \mathrm{mg}$ (in divided doses twice a day). Begin gradually $(0.25 \mathrm{mg}$ three or four times a day or $0.5 \mathrm{mg}$ twice a day) and titrate gradually upward. Lower doses can appear to work well initially but will often be associated with partial exacerbations of panic with time. Underdosing with these medications, because of fear of addicting patients, is the most common error family physicians make when treating panic disorder with benzodiazepines.

\section{Modifications for Patients on Medication Benzodiazepines}

If the patient is taking a benzodiazepine on a regular schedule, that schedule should be continued for at least the first 3 months so that withdrawal symptoms do not complicate or interfere with antipanic response to antidepressants. The benzodiazepine should be prescribed using a pharmacokinetically appropriate schedule to minimize daily withdrawal or interdose anxiety (alprazolam 4 times daily; clonazepam 2 times daily). After the patient has been taking antidepressants for 3 months, a tapered withdrawal of the benzodiazepine can be started, as described under Maintenance Treatment. If the patient is taking a benzodiazepine on an as-needed basis (four or fewer times a week), the patient should minimize use and attempt to stop gradually during the first few months of treatment with antidepressants.

\section{Antidepressants}

Optimize the dose of the antidepressant with dosage adjustments unless there is evidence of clear nonresponse to an adequate dose, the patient cannot tolerate the side-effects, or the patient wants to discontinue the medication. Table 5 displays a dosing schedule. If the patient has an inadequate response or complains of side effects, use the algorithm for the selection of medication. 
Table 4. Recommendations for Managing Side Effects of Pharmacotherapy for Panic Disorder.

\begin{tabular}{|c|c|}
\hline Problem & Suggested Management \\
\hline Insomnia & $\begin{array}{l}\text { Move dosing to early part of day } \\
\text { Add trazodone } 50-200 \mathrm{mg} \text { at bedtime } \\
\text { In men concerned about priapism, use } \\
\text { zolpidem (Ambien) } 10 \mathrm{mg} \text {, if there are } \\
\text { no concerns regarding abuse } \\
\text { Add nortriptyline } 25-50 \mathrm{mg} \text { at bedtime } \\
\text { Switch antidepressant to paroxetine or } \\
\text { fluvoxamine; nefazodone as later } \\
\text { option }\end{array}$ \\
\hline Nausea and diarrhea & $\begin{array}{l}\text { Take with food } \\
\text { Encourage patient persistence (should } \\
\text { reduce with time) } \\
\text { Reduce dose for } 4 \text { - } 7 \text { days, then rein- } \\
\text { troduce higher dose } \\
\text { Switch antidepressant (to another SSRI } \\
\text { or nortriptyline) } \\
\text { Add nizatidine-famotidine (Axid/Pep- } \\
\text { cid) for dyspepsia; diphenoxylate-- } \\
\text { atropine (Lomotil), acidophilus for } \\
\text { diarrhea }\end{array}$ \\
\hline Sedation & $\begin{array}{l}\text { Move dosing to bedtime } \\
\text { Encourage patient persistence (might } \\
\text { reduce with time) } \\
\text { Switch antidepressant (eg, to fluoxetine } \\
\text { or sertraline) }\end{array}$ \\
\hline $\begin{array}{l}\text { Delayed ejaculation, } \\
\text { anorgasmia }\end{array}$ & $\begin{array}{l}\text { Add buspirone } 10 \mathrm{mg} \text { twice a day } \\
\text { Add bupropion } 75 \mathrm{mg} \text { every morning } \\
\text { to twice a day } \\
\text { Add amantadine } 100 \mathrm{mg} \text { two to three } \\
\text { times a day } \\
\text { Consider weekend drug holidays (will } \\
\text { not work with fluoxetine) } \\
\text { Switch to nefazodone }\end{array}$ \\
\hline
\end{tabular}

SSRI - selective serotonin reuptake inhibitor.

\section{Regular, Low-Dose Sedating Antidepressants}

Nortriptyline, amitriptyline, doxepin, or trazodone may be continued at low bedtime doses for the first several months or, if needed, for the long term to avoid exacerbating sleep disturbance. If these antidepressant medications are administered concomitantly with SSRIs, however, paroxetine and fluoxetine are more likely than fluvoxamine or sertraline to increase levels of the tricyclic antidepressants because of cytochrome P-450 2D6 enzyme inhibition.

\section{Thymoleptics}

For the patient with bipolar mood disorder who has panic attacks, valproic acid (aim for blood levels of $50-100 \mu \mathrm{g} / \mathrm{mL}$ ) would be the treatment of choice because open case series findings suggest it has some antipanic efficacy. ${ }^{26}$ The newer anticonvulsant, gaba-pentin, is another excellent choice, using $900-2100 \mathrm{mg}$ in three divided doses (no blood level measurements required). If the patient's condition is stabilized with lithium, however, this medication should not be changed. In both cases adjunctive treatment with a benzodiazepine should be considered as the first choice, especially for patients who have a history of rapid cycling (ie, more than 3 to 4 highs and lows per year), because antidepressants can increase mood cycling or precipitate mania.

\section{Titration}

Table 5 displays a specific schedule for each medication. Dose increases at week 1 are predicated on no side effects. Dose increases at week 3 may be avoided if the patient has an early excellent response. For patients who have only a partial response by week 6 and for whom there is a clear need for further improvement, doses should be pushed to the top dose indicated and continued for another 6 weeks.

\section{Management of Side Effects}

Management of side effects can include, aside from routine dose reduction with an attempt to preserve efficacy, substitution of another recommended antidepressant that has a more benign side-effect profile. Comparative side effects for the medications are found in Table 3, and strategies for management of common side effects of SSRIs in particular are outlined in Table 4.

\section{Indications for Psychiatric Consultation}

A psychiatrist should be consulted for any of the following reasons:

Severe suicidal ideation: The patient has not simply thoughts but impulse, intent, or a specific plan regardless of a stated wish not to commit suicide.

Intolerable side effects: A patient has such severe problems with side effects that he or she is unable to take an adequate dose of the prescribed medication and has had to be switched to several (ie, more than two) medications because of similar intolerability.

Nonadberence: The patient, despite an absence of severe side effects, for whatever reason does not wish to continue taking medication. This decision might be related to marked symptom remission or despite persistent symptoms. The psychiatrist will advise whether medication can be discontinued in light of the patient's history.

No response by week 6: There are indications af- 
Table 5. Medication Dosing Schedule for Treatment of Panic Disorder.

\begin{tabular}{|c|c|c|c|c|c|c|}
\hline Medication & Begin & Week 1 & Week 2 & Week 3 & Week 4 & Top Doses \\
\hline Fluoxetine & $5 \mathrm{mg}$ qam* & $10 \mathrm{mg}$ & $20 \mathrm{mg}$ & $20 \mathrm{mg}$ & $20 \mathrm{mg}$ & $40 \mathrm{mg}$ \\
\hline Fluvoxamine & $25 \mathrm{mg} \mathrm{bid}$ & $50 \mathrm{mg}$ bid & $50 \mathrm{mg}$ bid & $75 \mathrm{mg}$ bid & $75 \mathrm{mg}$ bid & $150 \mathrm{mg}$ bid \\
\hline Paroxetine & $10 \mathrm{mg}$ qam & $20 \mathrm{mg}$ & $30 \mathrm{mg}$ & $40 \mathrm{mg}$ & $40 \mathrm{mg}$ & $50 \mathrm{mg}$ \\
\hline Sertraline & $25 \mathrm{mg}$ qam & $50 \mathrm{mg}$ & $50 \mathrm{mg}$ & $100 \mathrm{mg}$ & $100 \mathrm{mg}$ & $200 \mathrm{mg}$ \\
\hline Venlafaxine & $12.5 \mathrm{mg}$ bid & $25 \mathrm{mg}$ bid & $50 \mathrm{mg}$ bid & $50 \mathrm{mg}$ bid & $75 \mathrm{mg}$ bid & $150 \mathrm{mg}$ bid \\
\hline Nortriptyline & $25 \mathrm{mg} \mathrm{qhs}^{\dagger}$ & $50 \mathrm{mg}$ qhs & $75 \mathrm{mg}$ qhs & $75 \mathrm{mg}$ qhs & $100 \mathrm{mg}$ qhs & $125 \mathrm{mg}$ qhs \\
\hline Nefazodone & $50 \mathrm{mg}$ bid & $75 \mathrm{mg}$ bid & $100 \mathrm{mg}$ bid & $150 \mathrm{mg}$ bid & $150 \mathrm{mg}$ bid & $250 \mathrm{mg}$ bid \\
\hline
\end{tabular}

qam - every morning, bid - twice a day, qhs - at bedtime.

*If significant insomnia or agitation, reduce to $2 \mathrm{mg}$ qam. Then increase to $4 \mathrm{mg}, 6 \mathrm{mg}, 10 \mathrm{mg}$, and $20 \mathrm{mg}$ at end of each subsequent week. If insomnia or agitation, reduce to $10 \mathrm{mg}$ qhs, up-titrate by $10 \mathrm{mg}$ every 2 - 3 days to $50 \mathrm{mg}$, then resume usual up-titration.

ter the fifth week of treatment of less than 25 percent response (improvement on at least one of the measures of either anticipatory anxiety, panic frequency, or phobia). This timeline is based on pilot data indicating that in depressed patients failure to improve by at least 25 percent by week 6 predicts poor long-term response with 95 percent accuracy. ${ }^{27}$

\section{Maintenance Treatment \\ General Recommendation}

Patients should be encouraged to stay on pharmacotherapy for at least 1 year. If the patient expresses a strong desire to discontinue medication, the decision should be approved only if none of the following conditions exists: (1) continued symptoms of either panic, anticipatory anxiety, or phobic avoidance; (2) major psychosocial stress; and (3) serious medical illness.

Patients wishing to discontinue medication in the face of any of these three situations must be alerted to the probability that symptomatic relapse is greatest if all of these conditions are present and least if none of them is present.

\section{Benzodiazepines}

Patients should be encouraged to discontinue benzodiazepine therapy if they are concurrently taking an antidepressant and their symptoms of panic, anxiety, and phobia have resolved. The taper can be initiated at 12 weeks (after acute treatment) if the symptoms have almost completely resolved. A taper rate of about 10 percent ( \pm 5 percent) per week is recommended, based on the most convenient increments of 0.5 or $0.25 \mathrm{mg}$. The taper should take 10 to 16 weeks, as studies have shown slower tapers produce less frequent withdrawal reactions. ${ }^{28,29}$ If symptoms reappear, the patient should be given the dosage that previously had provided symptomatic relief. After several weeks a slower taper can be initiated, if desired.

\section{Indefinite Maintenance}

Evidence clearly suggests that in the long term many patients with panic disorder continue to have symptoms of depression, moderate phobic avoidance, or a personality disorder, all independently predicting a less than optimal outcome. ${ }^{30} \mathrm{Cer}-$ tainly patients who remain symptomatic or are exposed to the additional stress of medical illness or patients who have relapsed after discontinuing treatment should continue taking their medication. If there are minimal side effects and the patient has symptoms of two of the above three conditions, medication should be continued.

\section{Medication Taper and Discontinuation}

Patients should be advised to stay on medication for at least 1 year. If patients insist on discontinuation, the following guidelines should be used.

Antidepressants should be tapered gradually during a 4-week period using a titration schedule in reverse of that followed when the patient started the medication. If symptoms reappear, the taper should be stopped and the dosage increased to the previous level at which symptoms were not present. Tapering the medication can begin again at a later time.

A discussion of tapering benzodiazepines is addressed under Maintenance Treatment.

Jack Gorman, MD, Deborah Cowley, MD, and Mark Pollack, $M D$, reviewed these guidelines from the psychiatric perspective; and Elizabeth Linn, MD, and Joseph Lieberman, MD, reviewed these guidelines from the family physician perspective regarding feasibility and advisability of implementing them in the primary care setting. 


\section{References}

1. Leon AC, Olfson M, Broadhead WE, Barrett JE, Blacklow RS, Keller MB, et al. Prevalence of mental disorders in primary care. Implications for screening. Arch Fam Med 1995;4:857-61.

2. Roy-Byrne P, Katon W, Broadhead WE, Lepine JP, Richards J, Brantley PJ, et al. Subsyndromal ("mixed") anxiety - depression in primary care. J Gen Intern Med 1994;9:507-12.

3. Spitzer RL, Kroenke K, Linzer M, Hahn SR, Williams JB deGruy FV 3rd, et al. Health related quality of life in primary care patients with mental disorders: Results from the PRIME-MD 1000 Study. JAMA 1995;274:1511-7.

4. Shear MK, Schulberg HC. Anxiety disorders in primary care. Bull Menninger Clin 1995;59(2 Suppl A): A73-85.

5. Katerndahl DA, Realini JP. Where do panic attack sufferers seek care? J Fam Pract 1995;40:237-43.

6. Ormel J, Koeter MW, van den Brink W, van de Willige G. Recognition, management, and course of anxiety and depression in general practice. Arch Gen Psychiatry 1991;48:700-6.

7. Sheehan DV. Current concepts in psychiatry: panic attacks and phobias. N Engl J Med 1982;307:156-8.

8. Leon AC, Olfson M, Portera L. Service utilization and expenditures for the treatment of panic disorder. Gen Hosp Psychiatry 1997;19:82-8.

9. Markowitz JS, Weissman MM, Ouellette R, Lish JD, Klerman GL. Quality of life in panic disorder. Arch Gen Psychiatry 1989;46:984-92.

10. Sherbourne CD, Hays RD, Wells KB. Personal and psychosocial risk factors for physical and mental health outcomes and course of depression among depressed patients. J Consult Clin Psychol 1995;63: 345-55.

11. Fifer SK, Mathias SD, Patrick DL, Mazonson PD, Lubeck DP, Buesching DP. Untreated anxiety among adult primary care patients in a health maintenance organization. Arch Gen Psychiatry 1994;51: 740-50.

12. Merideth L, Sherbourne C, Jackson C, Camp P, Wells K. Treatment typically provided for comorbid anxiety disorder. Arch Fam Med 1997;6:231-7.

13. Ray WA, Blazer DG 2d, Schaffner W, Federspiel CF, Fink R. Reducing long term diazepam prescribing in office practice. A controlled trial of educational visits. JAMA 1986;256:2536-9.

14. Roy-Byrne PP. Benzodiazepines: dependence and withdrawal. In Roy-Byrne PP, Cowley DS, editors. Benzodiazepines in clinical practice: risks and benefits. Washington, DC: APA Press, 1991:131-54.

15. Composite international diagnostic interview (CIDI. Version 1.0). Geneva, Switzerland: World Health Organization, 1990.

16. American Psychiatric Association. Diagnostic and statistical manual of mental disorders. 4th ed. DSM-IV. Washington, DC: American Psychiatric Press, 1994.
17. Spitzer RL, Williams JB, Kroenke K, Linzer M, deGruy FV 3rd, Hahn SR, et al. Utility of a new procedure for diagnosing mental disorders in primary care. The PRIME-MD 1000 study. JAMA 1994; 272:1749.

18. Roy-Byrne PP, Geraci M, Uhde TW. Life events and the onset of panic disorder. Am J Psychiatry 1986;143:1424-7.

19. Wade SL, Monroe SM, Michelson LK. Chronic life stress and treatment outcome in agoraphobia with panic attacks. Am J Psychiatry 1993;150: 1491-5.

20. Loebel AD, Hyde TS, Dunner DL. Early placebo response in anxious and depressed patients. J Clin Psychiatry 1986;47:230-3.

21. Shear MK, Brown TA, Barlow DH, Money R, Sholomskas DE, Woods SW, et al. The Multicenter Collaborative Panic Disorder Severity Scale. Am J Psychiatry 1997;154:1571-5.

22. DeMartinis NA, Schweizer E, Rickels K. An openlabel trial of nefazodone in high comorbidity panic disorder. J Clin Psychiatry 1996;57:245-48.

23. Pollack MH, Worthington JJ 3rd, Otto MW, Maki KM, Smoller JW, Manfro GG, et al. Venlafaxine for panic disorder: results from a double-blind, placebocontrolled study. Psychopharmacol Bull 1996;32: 667-70

24. Altshuler LL, Post RM, Leverich GS, Mikalauskas $\mathrm{K}$, Rosoff A, Ackerman L. Antidepressant-induced mania and cycle acceleration: a controversy revisited. Am J Psychiatry 1995;152:1130-8.

25. Barlow DH, Lehman CL. Advances in the psychosocial treatment of anxiety disorders. Implications for national health care. Arch Gen Psychiatry 1996;53:727-35.

26. Keck PE Jr, Taylor VE, Tugrul KC, McElroy SL, Bennett JA. Valproate treatment of panic disorder and lactate-induced panic attacks. Biol Psychiatry 1993;33:542-6.

27. Nierenberg AA, McLean NE, Alpert JE, Worthington JJ, Rosenbaum JF, Fava M. Early nonresponse to fluoxetine as a predictor of poor 8-week outcome. Am J Psychiatry 1995;152:1500-3.

28. Pecknold JC. Discontinuation studies: short-term and long term. Presented at Panic and Anxiety: A Decade of Progress, Geneva, Switzerland, 19-22 June 1990.

29. Pecknold JC, Swinson RP, Kuch K, Lewis CP. Alprazolam in panic disorder and agoraphobia: results from a multicenter trial. III. Discontinuation effects. Arch Gen Psychiatry 1988;45:429-36.

30. Roy-Byrne PP, Cowley DS. Course and outcome in panic disorder: a review of recent follow-up studies. Anxiety 1994-95;1:151-60.

31. Preskorn SH. Comparison of the tolerability of bupropion, fluoxetine, imipramine, nefazodone, paroxetine, sertraline and venlafaxine. J Clin Psychiatry 1995;56(Suppl 6):12-21. 